\section{Self-concept and social support}

A key psychological relationship influencing academic success for male African American undergraduates

The significant strides to address racial and gender imbalances on university campuses in the United States uninter consure unintended consequences. in research into why males - African American males in particular - may underperform at university. Professor James Morris III, formerly at Lewis University, has explored a neglected area of study: how male students perceive their the social support from others, and whether this affects theiracademic performance.

\section{ver the last few decades, there in adjusting decades of racial der imbalances on university} campuses in the United States. Support programmes to address the lack of diversity in student and faculty reflective research, have been fruitful. Today, more women, including Black, Indigenous, People of Colour (BIPOC) women, attend college than ever before to the point that, according to the US Department of Education, female students now outnumber male studen on college campuses. However, this may have come at a cost: a deficit of interventions geared towards the uniqu challenges boys and men - especially

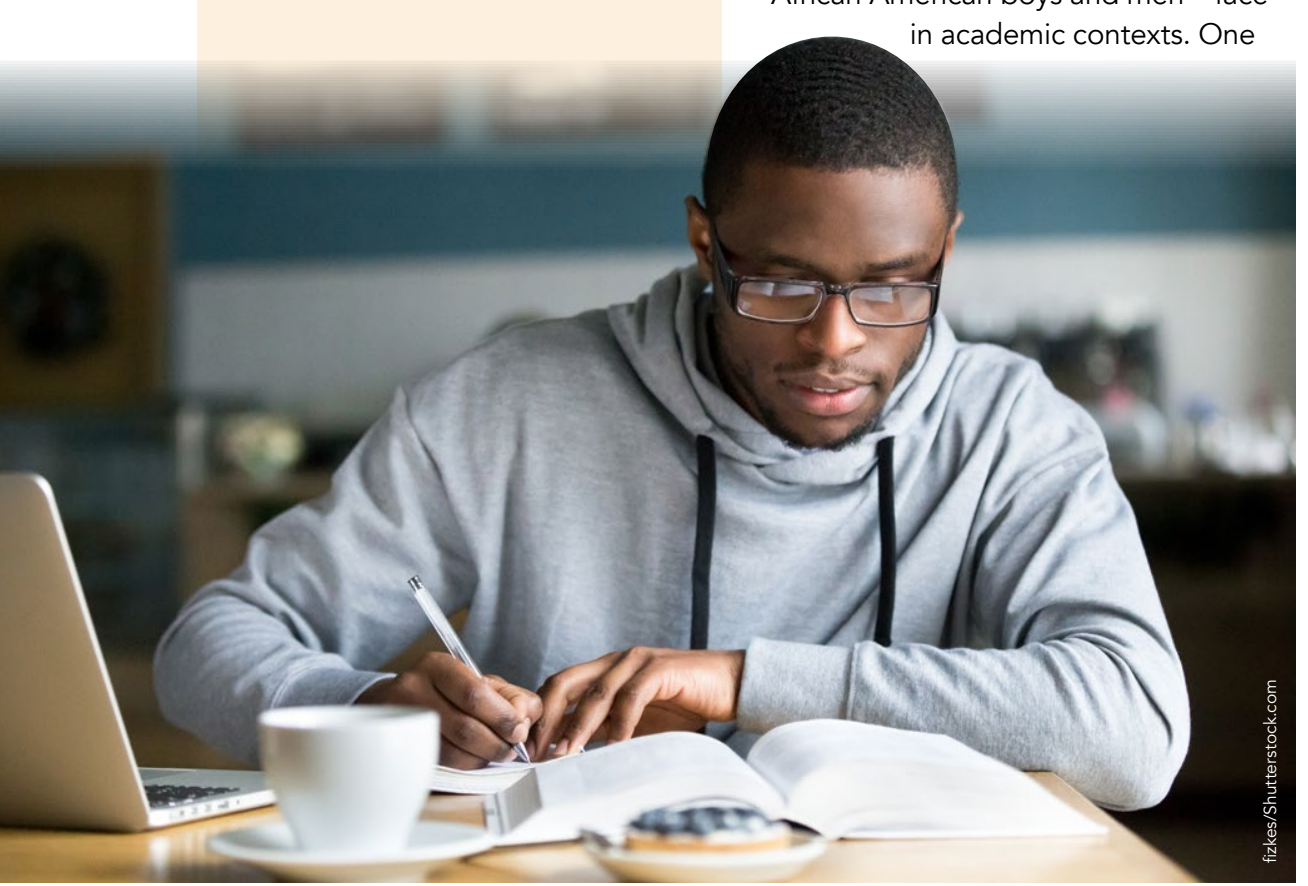

researcher has investigated what could be a key psychological relationship African American undergraduates.

Dr James Morris was formerly an assistant professor in the psychology department at Lewis University in Romeoville, just south of Chicago, where he trained graduate students in clinical mental health counselling. A series of conversations with two African American students first drew him to what seemed paradox. Students who demonstrated academic ability didn't necessarily translate that to academic achievement. This steered him towards a neglected area of research: the link between male African American students' academic self-concept, how they perceived social support, and the potential impacts these had on theris a adomic performance. His disquieting insights and sounded a call for further urgent research.

\section{ACADEMIC SELF-CONCEPT AND} SOCIAL FORMS OF SUPPORT Self-concept - the way people view themselves - is a well-researched area in psychology, with significant research devoted to issues of physical self-concept, social self-concept, and thletic self-concept. On the other hand, academic self-concept - an individual's awareness of him or herself in academic achievement circumstances - is a nascent and contested field whether academic self-concept shapes whether academic self-concept shapes academic performance or vice versa.
They broadly agree that the two are

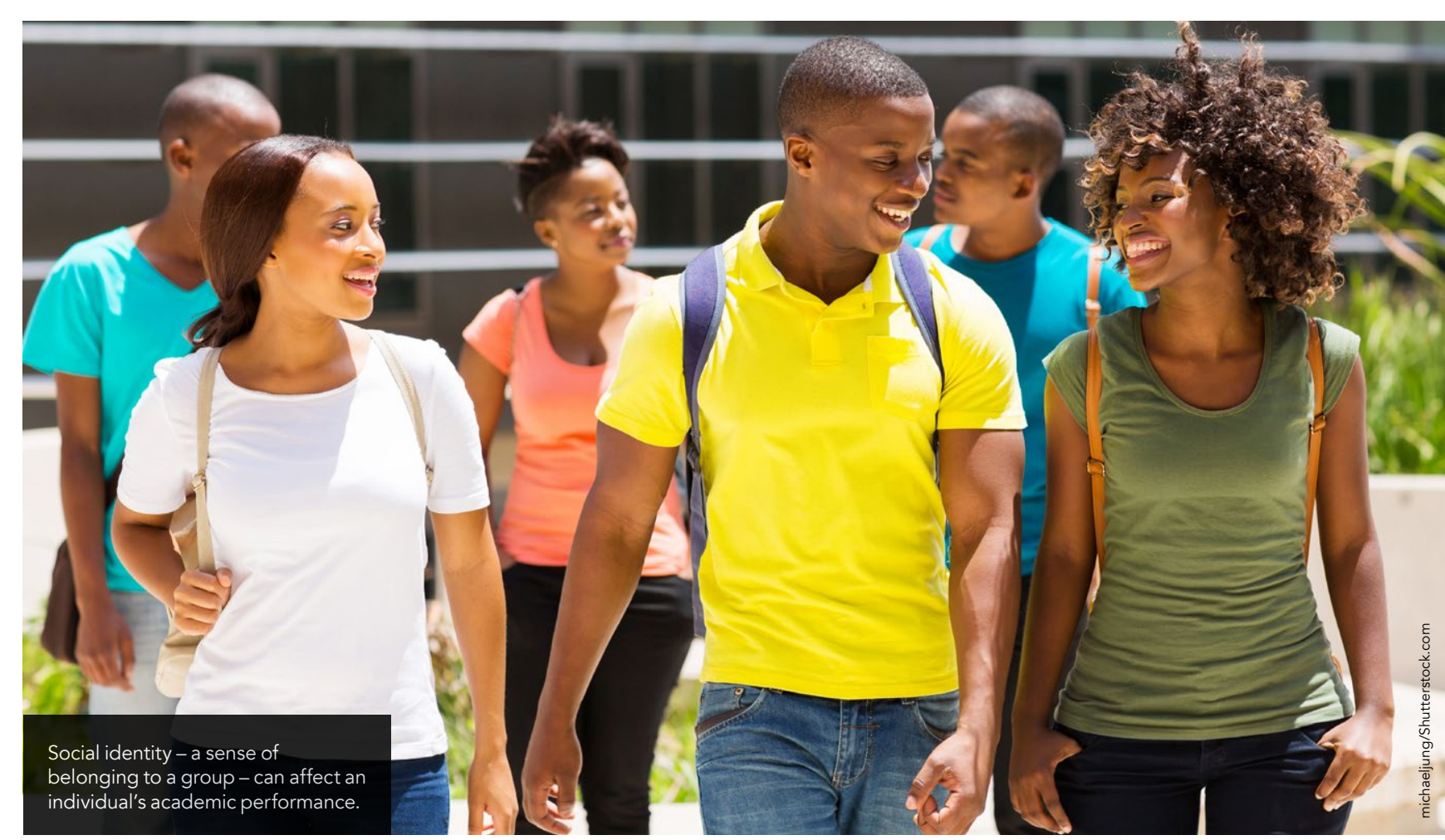

connected and that academic selfattitudes and efforts of the students toward their education. A student who perceives themselves as an academic underperformer, especially compared to their peers, may well live up to those perceptions. This is where another part of the puzzle fits in.

It's probably fair to say that few students excel without support. This support can come in various form There is clear, tangible support, financial assistance financial assistance technology, but it is the more it is the more
social forms of support that can support that can
have the most

impact. Emotional support from family, friends, and broader social groupings is essential, as is informational suppor - the advice and guidance from educators and other authorities. But there are other forms of social support, such as the companionship provided by a sense of belonging and identity. Studies substantiate common sense: the existence, or absence, of suppo can affect an individual's academic performance. But what about how

The blurred line between perception for centuries, and psychologists are drawn to how we construct our own realities based on perceptions. In the specific field of self-construct shows that pirls tend to perceive more social support from their socia more social support from their socia - especially their peers - compared to boys. Girls tend to around empathetic support, whereas boys tend to build larger peer circles

Students who demonstrated academic ability didn't necessarily

that male African American students didn't seem to achieve the levels their abilities suggested?

\section{BETWEEN PERCEPTION} AND REALITY

out to investigate this in a study among male undergraduates of all races at two private midwestern universities. He was interested in examining the relationship between percicions of social support and academic self-concept among between the type of social support ey received and perceptions of
academic selfconcept. His research was not purely academic in purpos

suggests that girls and boys differ in their reactions to social support around academic achievement. Socia support in the face of poor academic peftormance tends to encourage girls to do better, while boys are more have an impact on how girls and boys develop academic self-concept. Give that research also shows that social identity is a significant influence among be at the heart of Morris' observation mental health counselling, he saw the value in informing best practices for instructional strategies and training for fellow counselling professionals working in academic and clinical settings, especially those addressing the unique needs and challenges faced by male African American students.

Morris decided on a questionnairebased correlational research design. this wo th in notigate corelations 


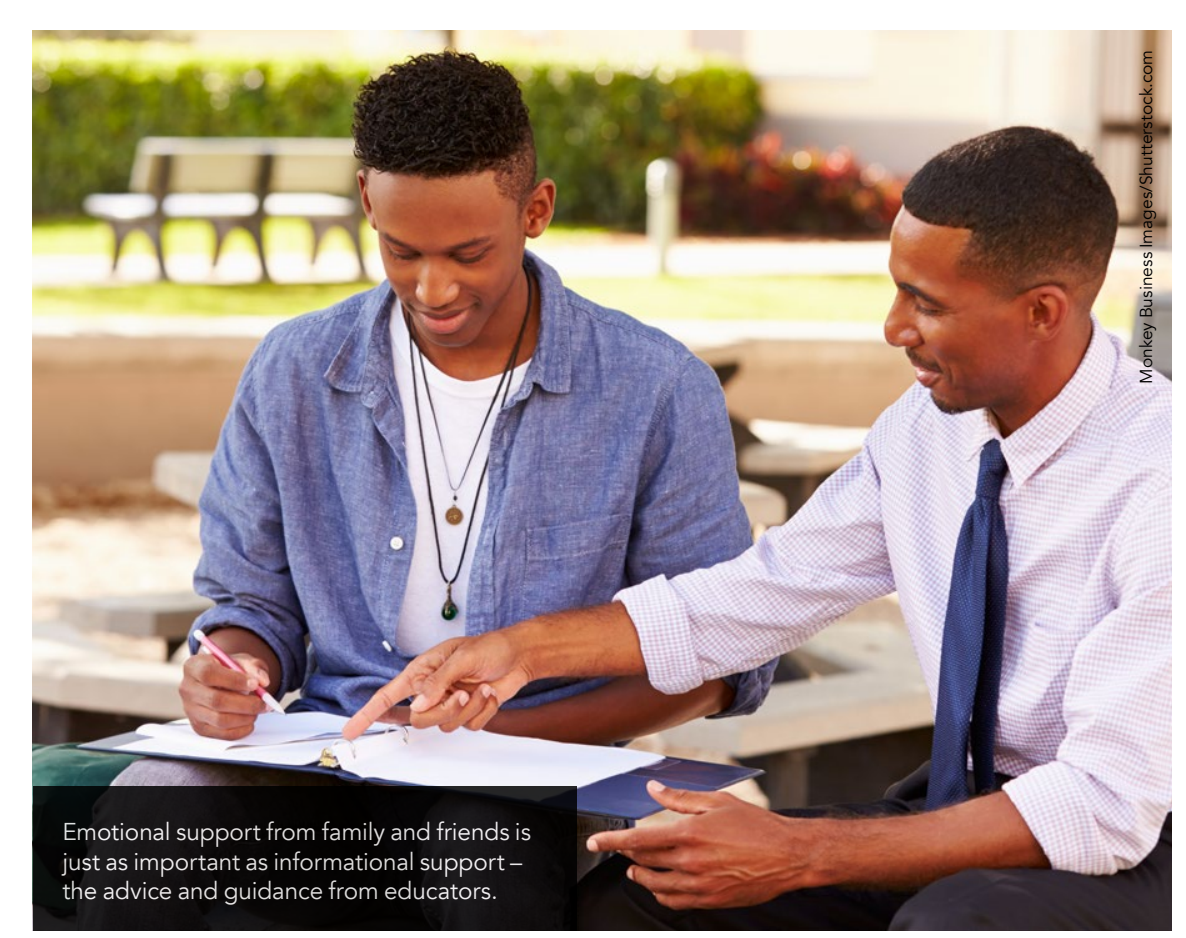

academic self-concept, no single kind of social support - from famly, friends the more significant.

This latter insight may seem frustrating academic self-concept in male students, but they should draw encouragement from the overall outcome. According to Morris, it can now be said with greater clarity that there is a relationship between academic self-concept and social support. That is true, and the results also help fill the void in research into why male students may underperform at university. As to why specifically male African American students who demonstrate academic ability don't necessarlly Morris highlights that only $132 \%$ of the Morris highlights that only $13.2 \%$ of the

between variables that he wasn't He identified the variables in three key questions. Firstly, what is the difference in student perceptions of social suppo among male undergraduates across different year levels in university? Secondly, what is the relationship between academic self-concept and student perceptions of social support among male undergraduates? And, thirdly, what is the relationship between academic self-concept and the type of social support ma undergraduates received? Three sources of support interested Morris: family, friends, and
significant other.

A total of 357 students received a package with a basic demographic questionnaire and two self-assessments. The sole inclusion criteria were that they were male and enrolled as undergraduates at the time of the study The demographic questionnaire provided ethnic background, age and sex, year in university, intended degree major, and self-reported grade point average. To assess their academic self-concept, a 40-tem Academic Sel-Concept Scale (ASCS) included statements such as 'Most courses are very easy for me' and ' I am better than the average college stude 1 rom 1 (sto rily disgre) to 4 (stongly from 1 (strongly disagree) to 4 (strongly
Morris" correlational study clearly demonstrated that the greater a student's academic self-concept, the greater the perceived social support.

support, a 12-item Multidimensional Scale of Perceived Social Support included statements such as 'My family really tries to help me' and 'I get the emotional support I need from my family'. Of the 357 undergraduates targeted, 86

\section{contained completely valid responses.}

\section{CORRELATIONS WITH A TWIST} One of the more intriguing outcomes of the study was that there was hardly any difference in the students' perceptions of social support over more and no less social support than between academic self-concept and student perceptions of social support Morris' correlational study clearly demonstrated that the greater a student's academic self-concept, the greater the perceived social support. On the relationship between academ self-concept and the type of social support male undergraduates receive the study showed that, whereas

American. He suggests that similar studies be conducted at universities with a substantial enough population of African American students to focus on that group.

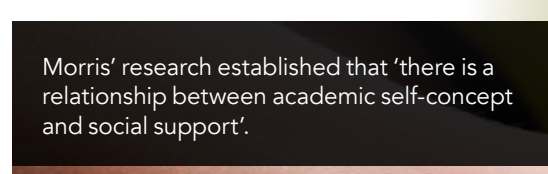
returned completed sunveys, of which 76 study. First-year students perceived no final-year students. On the relationship for a critical influencing point to develop

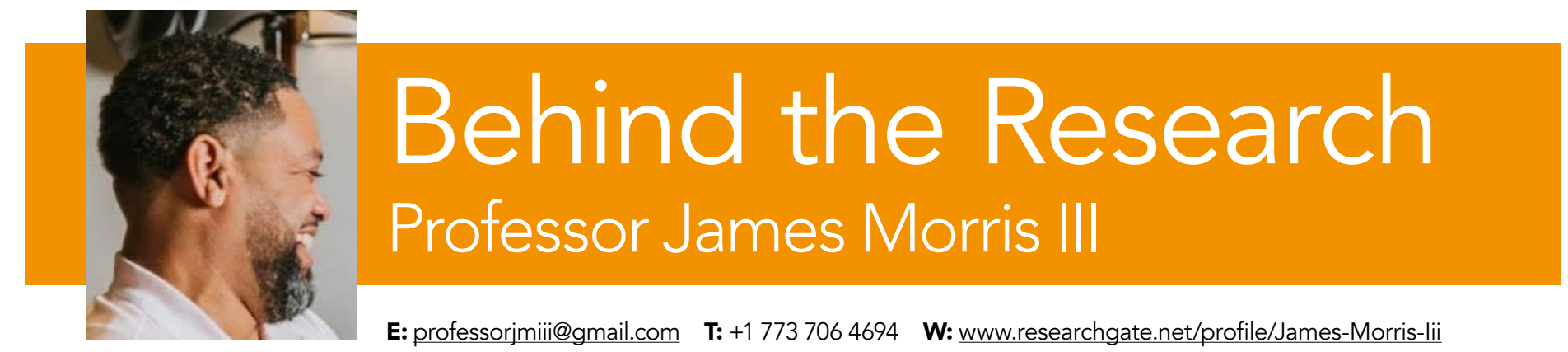

\section{Research Objectives}

Professor Morris examines the relationship between male students' academic self-concept and perception of social support

\section{Detail}

Bio

Dr James Morris was an assistant professor in the Psychology Department at Lewis University from 2014 to 2021, where he was largely responsible for the training of
graduate students in Clinical Mental Health Counselling. graduate students in Clinical Mental Health Counselling. a behavioural health facility in the Chicago area.
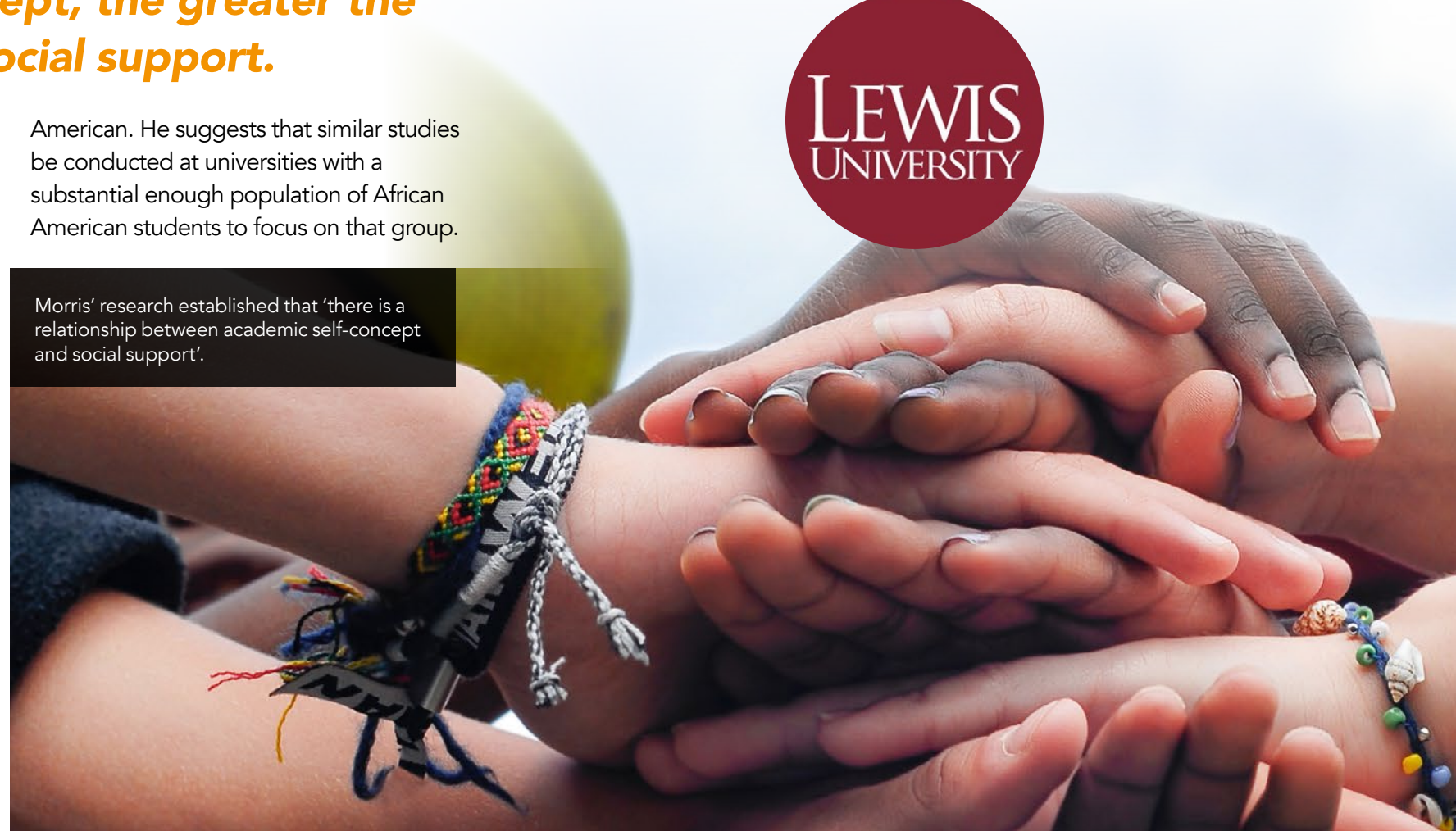

UNIVERSTIY
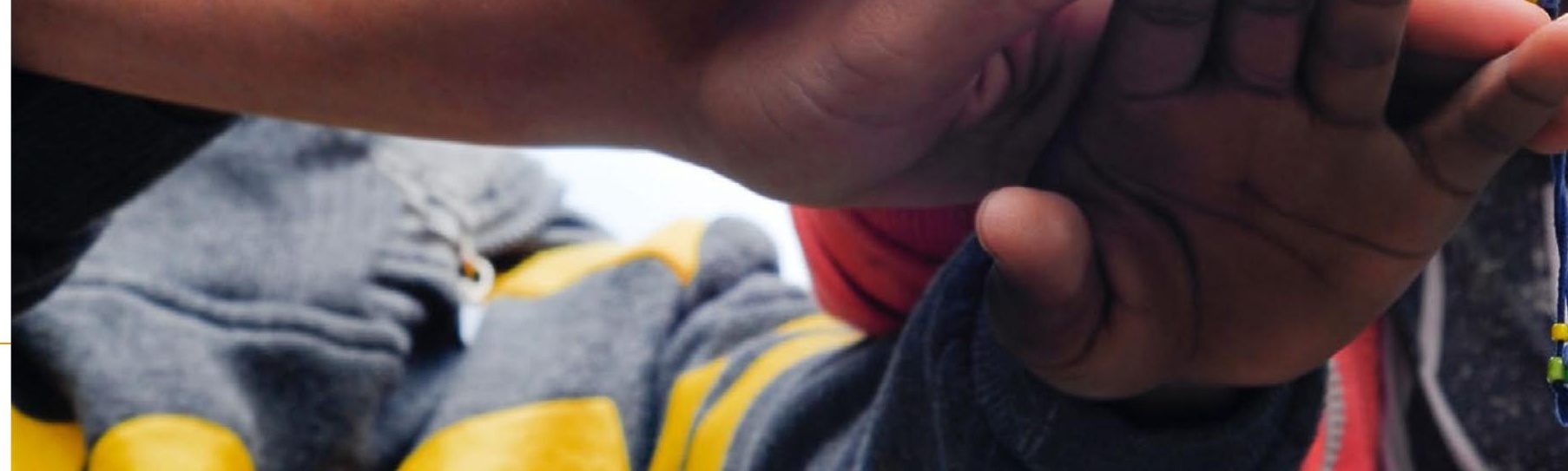

\section{References}

Morris III, J, (2020) Male perceptions of support and academic self-concept: A correlational study. Journal of Counseling in
Illinois (JCI), 6(1), 41-53.

\section{Personal Response}

If you were to repeat this study at a university where undergraduates, what key adjustments would you make?

II The psychology of young men with regards to their academic and social interactions guides the scope of
my future research, with an emphasis on young men of colour. The major problem that seems likely to arise when considering the correlation between ability and
achievement would be recognising the role of perceived achievement would be recognising the role of pupport in the instance of a weakened bond
social son the possibility of strengthening achievement through represents a noteworthy research endeavour.
Comparative analysis of male BIPOC students' Comparative analysis of male $\mathrm{BPOC}$ students
perceptions of social support and academic concept at predominantly white institutions versus historically black colleges and universities may also be a particularly fruitful area of exploration. Noteworthy, social support primarily
entails an issue relative to a person's external frame of entails an issue relative to a person's external frame of aid an individual in the successful navigation of academia. There exist speculations that social support and external frames of reference could mitigate self-doubt, raising a worthy point to address in subsequent research efforts. of the real -life encounters of the students, to help create an informed understanding regarding their perception of social support. That is, what has occurred in the lived experiences of male BIPOC students may provide in future research through the lens of perceived support
and academic self-concept. one's academic ability and perception of social support 